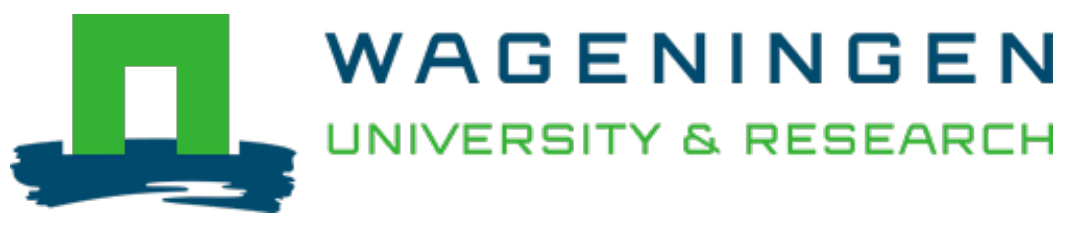

\title{
Application of PTR-TOF-MS for the quality assessment of lactose-free milk : Effect of storage time and employment of different lactase preparations
}

\author{
Journal of Mass Spectrometry \\ Bottiroli, Riccardo; Pedrotti, Michele; Aprea, Eugenio; Biasioli, Franco; Fogliano, Vincenzo et al \\ https://onlinelibrary.wiley.com/doi/abs/10.1002/jms.4505
}

This article is made publicly available in the institutional repository of Wageningen University and Research, under the terms of article $25 \mathrm{fa}$ of the Dutch Copyright Act, also known as the Amendment Taverne. This has been done with explicit consent by the author.

Article 25 fa states that the author of a short scientific work funded either wholly or partially by Dutch public funds is entitled to make that work publicly available for no consideration following a reasonable period of time after the work was first published, provided that clear reference is made to the source of the first publication of the work.

This publication is distributed under The Association of Universities in the Netherlands (VSNU) 'Article $25 \mathrm{fa}$ implementation' project. In this project research outputs of researchers employed by Dutch Universities that comply with the legal requirements of Article $25 \mathrm{fa}$ of the Dutch Copyright Act are distributed online and free of cost or other barriers in institutional repositories. Research outputs are distributed six months after their first online publication in the original published version and with proper attribution to the source of the original publication.

You are permitted to download and use the publication for personal purposes. All rights remain with the author(s) and / or copyright owner(s) of this work. Any use of the publication or parts of it other than authorised under article $25 \mathrm{fa}$ of the Dutch Copyright act is prohibited. Wageningen University \& Research and the author(s) of this publication shall not be held responsible or liable for any damages resulting from your (re)use of this publication.

For questions regarding the public availability of this article please contact openscience.library@,wur.nl 


\title{
Application of PTR-TOF-MS for the quality assessment of lactose-free milk: Effect of storage time and employment of different lactase preparations
}

\author{
Riccardo Bottiroli ${ }^{1,2}$ | Michele Pedrotti ${ }^{1,3}$ ( ) | Eugenio Aprea ${ }^{1,4}$ () |

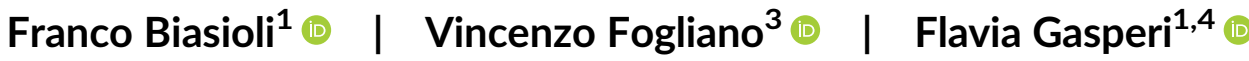

${ }^{1}$ Department of Food Quality and Nutrition, Research and Innovation Centre, Fondazione Edmund Mach, via E. Mach 1, San Michele all'Adige, TN, 38010, Italy

${ }^{2}$ Department of Agriculture and Food Science, University of Naples Federico II, Portici, NA, 80055 , Italy

${ }^{3}$ Food Quality and Design Group, Wageningen University, Wageningen, EV, 6700, The Netherlands

${ }^{4}$ Center Agriculture Food Environment, University of Trento/Fondazione Edmund Mach, via E. Mach 1, San Michele all'Adige, TN, 38010, Italy

\section{Correspondence}

Eugenio Aprea, Center Agriculture Food Environment, University of Trento/Fondazione Edmund Mach, via E. Mach 1, San Michele all'Adige, TN 38010, Italy.

Email: eugenio.aprea@unitn.it

\begin{abstract}
Lactose-free dairy products undergo several chemical modifications during shelf life because of the reactivity of glucose and galactose produced by the lactose enzymatic hydrolysis. In this study, proton transfer reaction-mass spectrometry (PTR-MS), coupled with a time-of-flight (TOF) mass analyzer, was applied to get an insight on the phenomena occurring during the shelf life of ultrahigh-temperature (UHT) lactose-free milk (LFM). UHT LFMs produced by three different commercial lactase preparations were evaluated during storage at $20^{\circ} \mathrm{C}$ over a 150 days period, sampling the milk every 30 days. Production was repeated three times, on three consecutive weeks, in order to take milk variability into consideration. Principal component analysis applied to the whole "volatilome" data demonstrated the capability of PTR-TOFMS in detecting the milk batch-to-batch variability: Freshly produced milk samples were distinguished based on the week of production at the beginning of shelf life. Additionally, a clear evolution of the volatiles organic compounds (VOCs) profiling during storage was highlighted. Further statistical analysis confirmed VOCs temporal evolution, mostly because of changes in methyl ketones concentration. Differences caused by the commercial lactases did not emerged, except for benzaldehyde. Altogether, data demonstrated PTR-TOF-MS analysis as a valuable and rapid method for the detection of changes in the VOCs profiling of UHT LFM.
\end{abstract}

\section{KEYWORDS}

lactose hydrolysis, lactose-free milk, PTR-MS, shelf life, VOCs

\section{1 | INTRODUCTION}

Complications related to lactose malabsorption have gathered the attention of both scientists and consumers in the recent past ${ }^{1}$. The increasing demand of healthier foods may push the preference for lactose-free milk (LFM) over conventional milk even among consumers, which are not lactose intolerant ${ }^{2}$. In this scenario, LFM have experienced a valuable increase in market shares ${ }^{3}$, and today represents a staple products in the diet of many consumers.
Milk sensory quality is driven by absence of odor and aftertaste, yet rejection might arise due unpleasant reaction occurring during shelf life ${ }^{4}$. Focusing on LFM, manufacturing is not trivial, and it poses additional challenges. For example, even though heating the milk at ultrahigh temperature (UHT) guarantees a prolonged shelf life ${ }^{5}$, the presence of free glucose and galactose produced by lactose hydrolysis renders the product susceptible to Maillard reaction ${ }^{6}$. Moreover, most UHT LFMs are produced by adding free soluble $\beta$-1,4-galactosidase (lactase) to the milk ${ }^{3}$. The commercially available options were found to contain arylsulfatase and proteolytic side activities, which can 
potentially modify the sensory quality of the milk during shelf life $\mathrm{e}^{2,7}$. In a study conducted by Stressler and coworkers (2016), for example, arylsulfatases from the $\beta$-1,4-galactosidase altered the odor of milk imparting a defect recognized as "cowshed-like." 8 Differently, proteolysis leads to the release of peptides and free amino acids in the milk. The phenomena may confer bitterness and astringency to the product $^{9}$, as well as provide further substrate for the formation of volatiles and nonvolatile compounds by Maillard reaction ${ }^{10}$.

Therefore, the importance of volatiles organic compounds (VOCs) in defining the quality of UHT LFM during shelf life is unquestionable. VOCs are responsible for the complexity of food flavor and aroma, as their release occur at each step of production, storage, and consumption $^{11}$. In this frame, it appears relevant to develop methodologies that allow a fast and reliable analysis of VOCs to monitor the quality of food products ${ }^{11}$. Proton transfer reaction-mass spectrometry (PTR-MS) was reported as a successful methodology for rapid, noninvasive, sensitive assessment of VOCs in food science ${ }^{11,12}$. The instrument exploits the ionization of VOCs by proton transfer from $\mathrm{H}_{3} \mathrm{O}^{+}$and registers a mass spectrum in which the measured signal and the mass/charge ratio $(\mathrm{m} / \mathrm{z})$ of the ions are plotted together ${ }^{13}$. In the dairy sector, applicability of PTR-MS has been previously verified on various products such as grana-type cheeses ${ }^{14,15}$, butter ${ }^{16}$, and yogurt ${ }^{17,18}$. When PTR is coupled with a quadrupole detector, distinction of molecules by PTR-MS is limited ${ }^{19}$. Better resolution and detection were achieved when the instrument was coupled with a time-offlight (TOF) mass spectrometer ${ }^{17}$.

Different approaches have been previously applied to evaluate the VOCs profiling of UHT LFM during shelf life. For example, dynamic headspace (DHS) gas chromatography mass spectrometry (GC-MS) was applied by Jansson and coworkers (2014) to investigate the differences in VOCs evolution between UHT LFM and conventional UHT milk over a 9-month storage ${ }^{20}$. Fifteen VOCs were quantified using external standards, and a sharper increase in concentration was registered by the lactose free. Together with other analysis, the study demonstrated stronger occurrence of Maillard reaction in LFM. As a solution, the same research group published an article proposing the addition of green tea extract (GTE) to UHT LFM to inhibit the proceeding of the reaction ${ }^{6}$. They studied the volatiles profile of UHT LFM added with GTE again by DHS GC-MS, and a significant decrease of specific VOCs was demonstrated. Troise and coworkers (2016) applied solid-phase microextraction (SPME) GC-MS for the evaluation of the VOCs in commercial UHT LFM samples ${ }^{7}$. In that case, external standard was injected, and the analysis was limited to specific VOCs. The results shown different temporal trend in the evolution of the compounds depending on the commercial samples. A different degrees of proteolytic activity in the lactases used by producers was suggested as main responsible for such variations.

From the studies mentioned above, it was clear that UHT LFMs are highly sensitive to changes in the "volatilome" during shelf life. The production process, the lactase preparations, and storage conditions play a crucial role in the definition of the final product quality. In this frame, the present study aims to investigate the application of PTR-TOF-MS to characterize how the VOCs profile of UHT LFM evolves during shelf life at $20^{\circ} \mathrm{C}$. By pairing PTR-TOF-MS with an auto-sampling system, we attempt a rapid characterization of the milk thanks to the high speed of the analysis, which allowed us to measure one sample per minute. To our knowledge, despite relevant published literature on the VOCs formation in UHT LFM during shelf life, this is the first time in which the task is performed by the rapid PTR-MS technique.

\section{MATERIALS AND METHODS}

\subsection{Chemical}

4-Methyl-2-pentanone (purity, $\geq 99 \%$ ) used as internal standard for GC-MS analysis was purchased from Sigma-Aldrich (Steinheim, Germany).

\section{2 | Preparation of the LFM samples}

Manufacturing of UHT LFM was carried out industrially on three consecutive weeks to include the milk batch-to-batch variability in the experimental design. A schematic drawing of each week of production is illustrated in Figure 1. Three different commercial lactase preparations were purchased and employed for the experiment (Lac1, Lac2, and Lac3). Semiskimmed milk was firstly pasteurized and employed for the production of the samples. The commercial lactase was added to the milk, and lactose conversion lasted for about 25 to 35 hours at refrigerated conditions. UHT treatment was then applied, and the milk was packed aseptically. A 150-day shelf life simulation was performed, storing the samples in a climate chamber at $20^{\circ} \mathrm{C}$ under controlled conditions. Samples were collected at time 0 and every 30 days and stored at $-80^{\circ} \mathrm{C}$ until the analysis was performed. A $5 \mathrm{~mL}$ of each UHT LFM was placed into 20-mL glass vials (Supelco, Bellefonte, PA, USA). Prior to analysis, samples were thawed at room temperature until thoroughly defrosted. Empty vials were used as blanks while the repeated measurement of a reference milk was used as quality control.

\section{3 | GC-MS measurements}

In concomitance with the PTR-TOF-MS measurements, to identify the compounds responsible for the mass peaks observed, HS-SPME GC-MS analysis has been carried out. The analysis was carried out both at the beginning and the end of the shelf life study (namely, at 0 and 150 days of storage) on the UHT LFMs from the first week production. Measurements were based on the methodology already applied by our research group in previous studies ${ }^{21}$. VOCs extraction was performed at $40^{\circ} \mathrm{C}$ for 60 minutes with a 2-cm divinylbenzene (DVB)-carboxen-polydimethylsiloxane (PDMS) SPME fiber. Volatiles compounds were desorbed at $250^{\circ} \mathrm{C}$ in the injector port of a GC interfaced with a mass detector operating in an electron ionization mode 


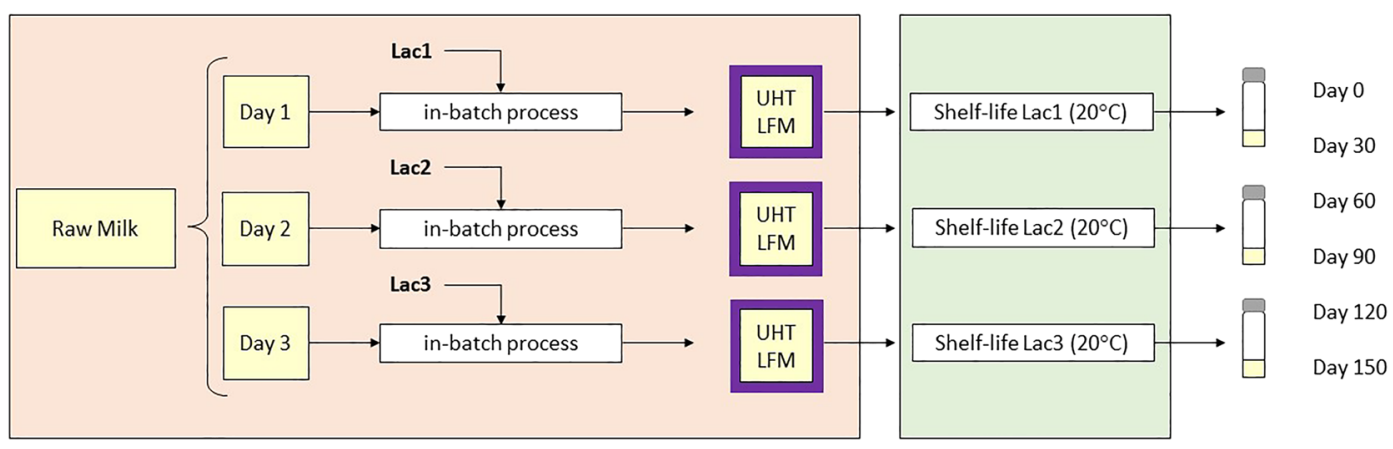

FIGURE 1 Simplified representation of the experimental design. Ultrahigh temperature (UHT) lactose-free milk (LFM) was produced adding the three different commercial lactases (Lac1, Lac2, and Lac3) prior to UHT treatment. Manufacturing of the three LFMs occurred on three consecutive days within the same week of production. The experiment was replicated three times (namely, on three different weeks of production) in the same manner in order to have three production replicates for each UHT LFM and take the milk batch-to-batch variability into consideration. All the LFM samples were stored at $20^{\circ} \mathrm{C}$ under controlled conditions for the shelf life study. As soon as after production ( 0 days of storage), sampling was then performed every 30 days until 150 days of storage

(70 eV). Mass scan ranged from $\mathrm{m} / \mathrm{z} 33$ to 300 (GC Clarus 500, PerkinElmer, Norwalk, CT). An auto-sampling system (CTC combiPAL, CTC Analysis AG, Zwingen, Switzerland) was used to manage the measurement in an automatic manner. An HP-Innowax fusedsilica capillary column (30 m, 0.32-mm inner diameter, $0.5-\mu \mathrm{m}$ film thickness; Agilent Technologies, Palo Alto, CA) was used for the separation of the compounds. Linear retention indices (RIs) were calculated injecting, under the same chromatographic conditions, C7-C30 n-alkane series (Supelco, Bellefonte, PA). Using the NIST-2014/Wiley 7.0 libraries combined to the calculated RIs, an identification of the VOCs was provided.

\section{4 | PTR-TOF-MS measurements}

The set up of the measuring conditions was based on PTR-MS procedures described elsewhere ${ }^{22}$. Briefly, a PTR-TOF-MS 8000 (Ionicon Analytik $\mathrm{GmbH}$, Innsbruck, Austria) operating in $\mathrm{V}$ mode (standard configuration of the instrument) was used for measuring the samples headspace. The following ionization conditions were set in the drift tube: extraction voltage of $24.3 \mathrm{~V}$, drift voltage of $628 \mathrm{~V}$, drift temperature of $110^{\circ} \mathrm{C}$, and drift pressure 2.78 mbar corresponding to an $\mathrm{E} / \mathrm{N}$ value of 128 Townsend $\left(1 \mathrm{Td}=10^{-21} \mathrm{~V} \mathrm{~m}{ }^{2}\right)$. The mass resolution $(\mathrm{m} / \Delta \mathrm{m})$ was higher than 3800 . All measurements were automatically performed using an auto-sampling system (Gerstel $\mathrm{GmbH}$, Mulheim am Ruhr, Germany) connected to the PTR-MS inlet, namely, a Polyetheretherketone (PEEK) capillary tube (inner diameter, $0.40 \mathrm{~mm}$ ), heated at $110^{\circ} \mathrm{C}$. Vials containing the milk samples were incubated at $50^{\circ} \mathrm{C}$ for 30 minutes prior to analysis. Three instrumental replicates were measured for each HLM UHT sample. Each vials was measured for 60 seconds (flow rate of $35 \mathrm{sccm}$ ) with an acquisition rate of one spectrum per second ( $m / z$ range: $21-300$ ).

\subsection{Peak selection and data handling}

Results of the extracted $\mathrm{m} / \mathrm{z}$ were expressed with three decimal places. The procedure of dead time correction, peak extraction, and internal calibration of the data was based on a previous articles published by Cappellin and coworkers $(2010)^{23}$. The following mass peaks were used for internal calibration: $21.0221\left(\mathrm{H}_{3} \mathrm{O}^{+}\right), 29.9974\left(\mathrm{NO}^{+}\right)$, and 203.9430 (1,3-diiodobenzene fragment). The latter was continuously injected as internal reference throughout the PTR-TOF-MS analysis using the PerMaSCal device (Ionicon, Innsbruck, Austria). The formula proposed by Lindinger et $\mathrm{al}^{24}$ was applied by assuming a constant reaction rate coefficient of $k_{R}=2 \times 10^{-9} \mathrm{~cm}^{3} /$ second to express the results in absolute concentrations (ppbV, part per billion by volume $)^{4}$. This approximation leads to a systematic error that in most cases was below $30 \%$ for all the compounds ${ }^{25}$. Mass spectra signals were averaged over 30 consecutive spectra.

\subsection{Statistical analysis of the results}

${ }^{13} \mathrm{C}$ isotopologues and interference masses were removed from the dataset. Mass peaks detected in the samples were compared with the blanks via Student $t$-test applying Bonferroni correction in order to select those mass peaks significantly higher than blank. On this reduced dataset, principal component analysis (PCA) was performed after log transformation and Pareto scaling to explore pattern in the data. Pareto scaling uses the square root of the standard deviation as scaling factor in order to penalize those variables having large standard deviations (reasonably noise signals). For data exploration, replicates of production were kept separated to visualize the different milk batches. Loadings considered relevant in defining the trends of the PCA, namely, the ones with values $\geq 0.15$ and $\leq-0.15$ on the first component and those $\geq 0.10$ and $\leq-0.10$ on the second component, were further considered in order to reduce the dimensionality of the dataset. Selected mass peaks on which a tentative identification was attempted were reported in a summary table (Table 2). The table was also implemented with those compounds discarded by the described dataset reduction procedure but revealed by the GC analysis. Mean \pm standard deviation of the three instrumental replicates coming from the three different batches of production $(n=9)$ was further 
considered for each selected peak mass. Two-way analysis of variance (ANOVA) with Tukey post hoc was applied when necessary to investigate the evolution of the selected VOCs in the UHT LFM samples. A $\alpha \leq 0.05$ was chosen as threshold for significant differences. Statistical analysis was performed using the software package STATISTICA 13.3 (StatSoft, Inc., Tulsa, OK, USA) and the R packages FactoMineR and factoextra.

\section{3 | RESULTS AND DISCUSSIONS}

\section{1 | VOCs fingerprinting by PTR-TOF-MS}

In total, 368 mass peaks were extracted from the PTR-TOF-MS spectra, and 268 mass peaks were found significantly higher than blanks. PCA was performed to explore the spatial distribution of the UHT LFM samples as function of the considered mass peaks. Pareto scaling was applied to adjust different fold changes among the variables and penalize the ones with large variation in the measurements, most likely associated to noise ${ }^{26}$. Figure 2 shows the score plot of the first and second principal components (PC1 and PC2) explaining, respectively, $43.81 \%$ and $10.90 \%$ of the total variance. The analysis distinguished the UHT LFM as function of the batch of production. Moreover, the effect of the storage time was also highlighted. At 0 days of storage, the three different replicates (weeks) of production were somehow separated. The effect seemed to be explained by the combination of PC1 and PC2. Batch-to-batch milk variability appeared not relevant at intermediate and final stages of shelf life. Batch-tobatch variability in UHT LFM was already reported by Jansson and coworkers $(2014)^{27}$. In that case, variations emerged because of initial differences in ketones concentration. Many factors can render the VOCs profile of milk variable among different batches of production.
For example, changes in composition of the pasture fed to cows can convey different aromas to the milk ${ }^{28}$. From the results, we can conclude that the applied PTR-TOF-MS methodology was appropriate to discriminate UHT LFMs coming from different batches of milk. Nevertheless, from the explorative analysis, the three commercial lactases (Lac1, Lac2, and Lac3) did not lead to a clear distinction of the samples, suggesting a similar VOCs profiling among the products during shelf life.

\section{2 | Mass peak identification by HS-SPME GC-MS}

HS-SPME GC-MS analysis was carried out in support to the tentative identification of the mass peaks detected by PTR-TOF-MS. A total of 24 VOCs were identified in the headspace of the UHT LFMs (Table 1). The profile was in line with the literature available on the topic ${ }^{7,27}$. The compounds detected by HS-SPME GC-MS with higher frequency were ketones. The class is considered a good indicator of deterioration of the milk upon heating, as their formation goes hand to hand with the severity of the treatment ${ }^{29}$. Ketones were followed by aldehydes in terms of incidence. Even in this case, all the four identified aldehydes were reported in UHT LFM by other authors ${ }^{27}$. Besides the detection in UHT milk straight after production, aldehydes and methyl ketones are important VOCs to monitor because of their contribuion to the stale and oxidize flavor of the milk during storage ${ }^{30}$.

Mass peaks considered relevant for the trends showed in the PCA (Figure 2) were investigated in more details, and those tentatively identified are summarized in Table 2. In supplementary material (S1) temporal trend of the selected mass peaks reported in Table 2, separated for each replicate of production and lactase preparation tested are reported as well. The identity of 11 VOCs was confirmed by the results of HS-SPME GC-MS analysis. Additionally, the table was also implemented with the mass peaks whose identification was attempted

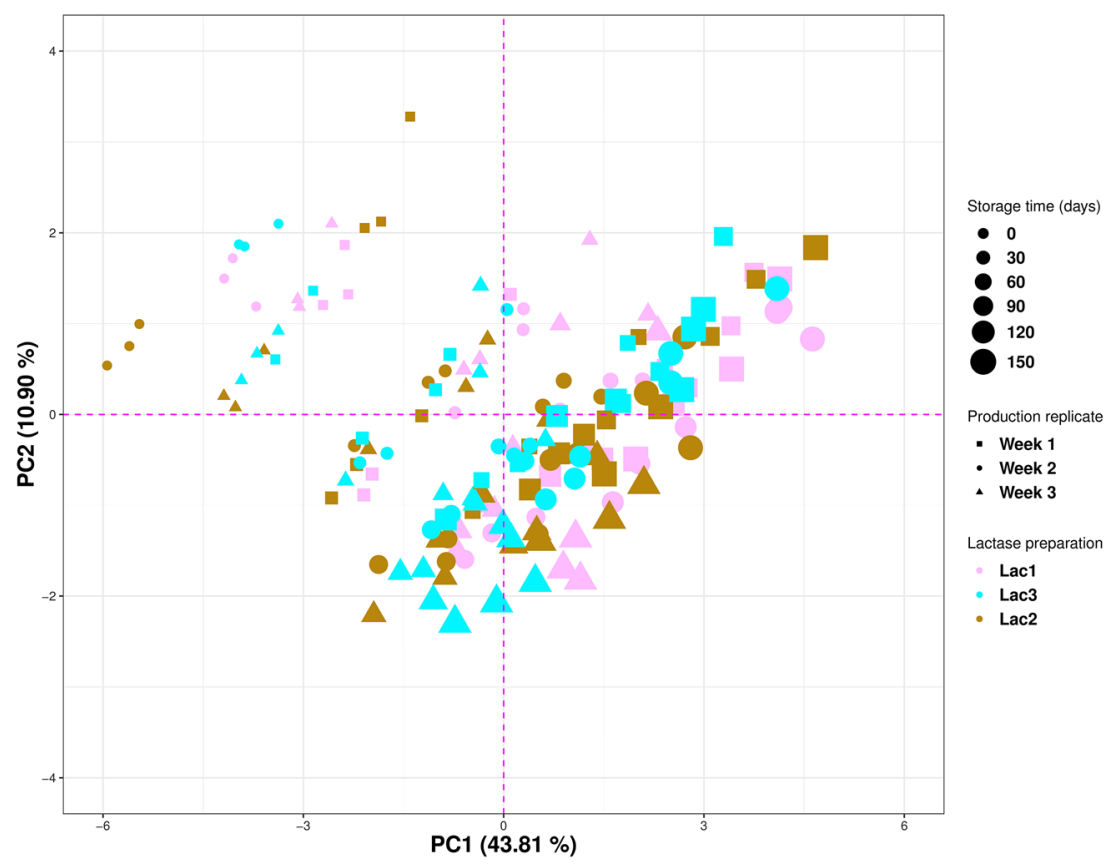

FIGURE 2 Principal component analysis (PCA) score plot of the first (PC1) and second (PC2) components, which describe, respectively, the $43.81 \%$ and $10.90 \%$ of the total variance. Analysis was performed on the Pareto scaled and mean-centered data including all the time points 
TABLE 1 Volatiles compounds identified by HS-SPME GC-MS in the headspace on UHT LFM produced along the first replicate (week) of production both at the beginning and the end of the shelf life study (namely, at 0 and 150 days, respectively)

\begin{tabular}{|c|c|c|}
\hline Volatile Compounds & $\mathbf{R t}^{\mathrm{a}}$ & $\mathrm{RI}^{\mathrm{b}}$ \\
\hline 2-Butanone ${ }^{c}$ & 2.67 & 909 \\
\hline 2-Methylbutanal & 2.86 & 920 \\
\hline 2-Pentanone & 4.02 & 985 \\
\hline Toluene & 5.47 & 1050 \\
\hline Dimethyldisulfide & 6.35 & 1087 \\
\hline Hexanal & 6.62 & 1099 \\
\hline Ethyll-benzene & 7.91 & 1138 \\
\hline 2-Heptanone & 9.66 & 1190 \\
\hline Xylene & 9.73 & 1192 \\
\hline 2-Nonanone & 16.56 & 1394 \\
\hline Nonanal & 16.69 & 1398 \\
\hline Benzaldehyde & 20.91 & 1531 \\
\hline 1-Octanol & 22.23 & 1574 \\
\hline 2-Undecanone & 23.13 & 1604 \\
\hline$\gamma$-Butyrolactone & 24.05 & 1636 \\
\hline Aceto-phenone & 24.77 & 1660 \\
\hline 2-Tridecanone & 29.12 & 1816 \\
\hline Dimethyl sulfone & 31.55 & 1908 \\
\hline Hexanoic acid & 31.10 & 1891 \\
\hline $\mathrm{p}$-Cresol & 36.18 & 2095 \\
\hline m-Cresol & 36.36 & 2102 \\
\hline Octanoic acid & 36.42 & 2105 \\
\hline$\delta$-Decalactone & 38.64 & 2199 \\
\hline Decanoic acid & 42.24 & 2295 \\
\hline
\end{tabular}

Abbreviations: GC-MS, gas chromatography mass spectrometry; HS-SPME, headspace solid-phase microextraction; LFM, lactose-free milk; UHT, ultrahigh temperature.

${ }^{\text {a }}$ Retention time (min).

${ }^{b}$ Linear retention index.

${ }^{\mathrm{C} C o m p o u n d s}$ tentatively identified matching the NIST-2014/Wiley 7.0 libraries.

on the basis of relevant literature, the chemical formula, and the fragmentation pattern ${ }^{22,31,32}$. This led to a total of 18 VOCs associated to a mass peak identified in the UHT LFMs headspace. Mass peak $\mathrm{m} / \mathrm{z}=73.064$ (associated to 2-butanone/butanal) was the reported compound, which registered the highest abundancy (ppbV) at the end of the shelf life period. It was followed by $\mathrm{m} / \mathrm{z}=69.070$, $\mathrm{m} / \mathrm{z}=63.026$, and $\mathrm{m} / \mathrm{z}=49.011$. These masses were associated, respectively, to isoprene, dimethyl sulfide (DMS), and methanethiol (MeSH). Some compounds were present at higher concentration but, as the trend shown by the PCA was not considered relevant and a match with the GC-MS results was not found, it was chosen to leave them out from the summary table. Mass peak $\mathrm{m} / \mathrm{z}=45.033$ is a clear example. It was associated to acetaldehyde, a well-known index of light oxidation in dairy products ${ }^{33}$. Its concentration in the headspace ranged between $3.58 \mathrm{ppbV}$ and $77.08 \mathrm{ppbV}$ throughout the storage of the UHT LFMs. However, the impact on the PCA (Figure 2) was tiny, so it was decided to exclude it from further statistical considerations.

\subsection{Effect of storage time on the VOCs profile}

Two-way ANOVA and Tukey honest significant difference (HSD) were performed to investigate the effect of storage time and commercial lactases on the reported mass peaks. The analysis highlighted the presence of significant differences among the UHT LFMs because of storage time. In fact, most of the reported mass peaks were found at significantly higher concentrations at the end of the storage (150 days of storage) compared with the freshly produced samples ( 0 days of storage). Mass peaks tentatively associated to methyl ketones registered a significant increase during storage for all the UHT LFMs produced with the three commercial lactases. All the methyl ketones detected by PTR-TOF-MS were also confirmed by the HS-SPME GCMS analysis, with the exception of the mass peaks $m / z=129.128$, associated to 2-octanone/octanal. It is not the first time that this VOC is reported in UHT milk ${ }^{34}$. However, in our study, the compound was detected at very low levels $(<0.05 \mathrm{ppbV})$. 2-Pentanone $(\mathrm{m} / \mathrm{z}=87.081)$ and 2-heptanone $(\mathrm{m} / \mathrm{z}=115.112)$ were the methyl ketones that experienced the most remarkable increase during shelf life. In the freshly produced samples, 2-pentanone was present in the range of 0.40 to $0.48 \mathrm{ppbV}$ and increased up to 1.23 to $1.40 \mathrm{ppbV}$ depending of the lactase preparation employed (Lac1, Lac2, and Lac3). 2-Heptanone followed a similar trend: It increased progressively from 0.55 to 0.60 ppbV, and it reached 1.22 to 1.35 ppbV after 150 days of storage. Significant increase of methyl ketones during shelf life was already described both for conventional and UHT LFM. Jansson et al (2014) reported higher rates of increase of methyl ketones in the latter ${ }^{20}$. Methyl ketones are formed upon heating either by the decarboxylation of $\beta$-keto fatty acids or the $\beta$-oxidation and decarboxylation of free saturated fatty acids ${ }^{35}$. Jensen et al (2015) estimated the class as good predictor for the development of "stale flavor" during shelf life of LFM"10.

Even though an overall increase in VOCs in UHT LFM was registered during storage, some mass peaks followed a different trend. Mass peak $\mathrm{m} / \mathrm{z}=49.011$, tentatively identified as MeSH decreases during storage, although the drop was not statistically significant when biological variability of the milk was considered. $\mathrm{MeSH}$ is formed from methional and contributes, together with other volatiles sulfur compounds, to the "cooked flavor" of pasteurized and UHT milk $^{36}$. Presence of free methional in the milk could therefore justify detection of $\mathrm{MeSH}$ in our experiment. Temporal decrease of $\mathrm{MeSH}$ is reasonable because it reflects the proceeding of oxidation, which might lead to the formation of DMS and $\mathrm{H}_{2} \mathrm{~S}^{36}$. Protein-bound methionine is also the precursor of DMS $(m / z=63.026)$, so its significant increase might be also associated with the decrease of MeSH during storage. Thus, the result indicated possible degradation of methionine during storage of UHT LFM, already reported in the literature and potentially imputable to the proteolytic side activity originally present in the commercial lactase preparations ${ }^{7}$. 


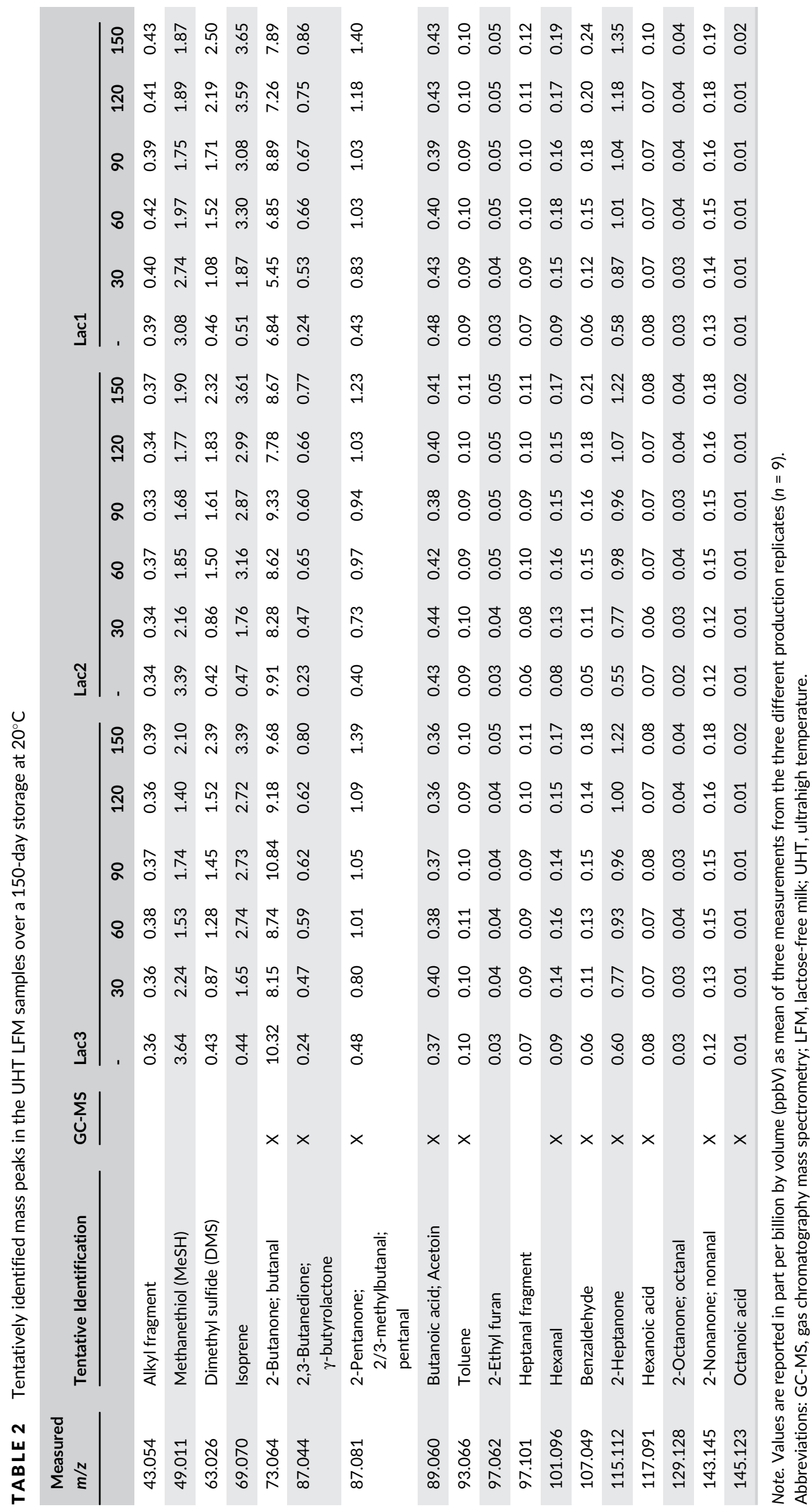




\subsection{Effect of the different types of commercial lactase preparations on the VOCs profile}

Quality losses in UHT LFM has been associated with presence of proteolytic and arylsulfatase activities in the commercially available lactase preparations. Thus, besides storage time, the effect of different commercial lactase preparations (Lac1, Lac2, and Lac3) on the VOCs profiling of UHT LFM was also investigated. Overall, almost all the mass peaks did not change significantly at each storage time based on the different lactases employed. At a first glance, the results might indicate that the tested commercial lactases were similar and led to an almost indistinguishable VOCs profile in the products. Alternatively, the manufacturing process might explain the similarity in VOCs profiling among the samples. The applied manufacturing process, so-called "in batch," relies on the inactivation of the lactase by heating the milk at UHT before packaging and storage $\mathrm{e}^{7,37}$. With regards to the proteolytic side activity of lactase, the literature lacks of information concerning the relative stability upon heating. A review published by Dekker and coworkers (2019) reported that, when lactose hydrolysis is performed before the thermal treatment, the proteolytic side activity of the lactase is inactivated ${ }^{37}$. The finding is in line with our results, and the similar VOCs profiles detected by PTR-TOF-MS analysis might be a consequence of the applied process for UHT LFM manufacturing. Nevertheless, the analysis of the variance revealed the presence of significant differences for the mass peak $\mathrm{m} / \mathrm{z}=107.049$. Basically, its concentration over time increased for all the UHT LFM samples following different trends (Figure 3). This means that for $\mathrm{m} / \mathrm{z}=107.049$, tentatively identified as benzaldehyde, the temporal evolution was dependent on the lactase preparations employed. UHT LFM produced with Lac1 and Lac2 were significantly higher in benzaldehyde both after 60 and 120 days of storage. At the end of the shelf life (150 days), Lac1 was the commercial lactase preparation causing the highest release of benzaldehyde in the UHT LFM headspace. The concentration was significantly higher than samples produced with Lac3 but not in

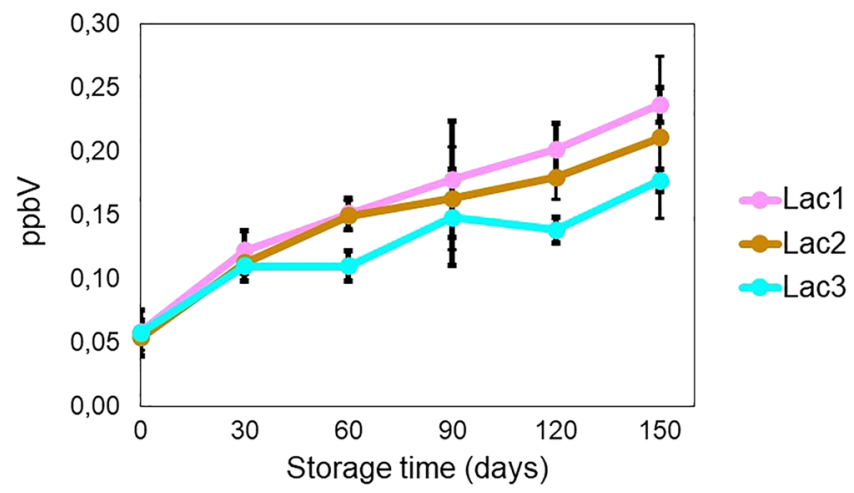

FIGURE 3 Time evolution (day 0-150) during storage at $20^{\circ} \mathrm{C}$ of the mass peak $\mathrm{m} / \mathrm{z}$ 107.048, tentatively identified as benzaldehyde, of ultrahigh temperature (UHT) lactose-free milks (LFMs) produced with three different commercial lactase preparations (Lac1, Lac2, and Lac3) comparison to Lac2. Benzaldehyde can be considered a thermally induced compound in milk ${ }^{38}$. The formation may occur alongside Maillard reaction starting from phenylalanine ${ }^{6}$. The mechanism involves the conversion of the amino acid to phenylacetaldehyde via Strecker degradation and subsequent oxidation to benzaldehyde ${ }^{39}$. Following this pathways, our results showed different extent of benzaldehyde formations possibly because of different degrees of proteolytic side activity in the tested lactases. A study published by Troise and coworkers in 2016 already reported changes of phenylalanine and benzaldehyde in a commercial UHT LFM produced by "in-batch" technology ${ }^{7}$. In that case, release of phenylalanine was minimum and seemed not related to an increase of benzaldehyde during shelf life. On the other hand, only one commercial milk was evaluated, and the lactase preparation employed by producers was unknown. Thus, further research on the link between phenylalanine and benzaldehyde is required. Eventually, the significant increase of benzaldehyde over time might suggest the heat stability of some proteolytic side activity natively present in the commercial lactase, another aspect that should be further investigated.

\section{4 | CONCLUSION}

In the present study, changes in the VOCs profile of UHT LFM during storage at ambient temperature were evaluated by PTR-TOF-MS coupled with a multipurpose auto-sampler. Applying PTR-TOF-MS, we significantly diminish the time of analysis. This allowed the design of a more complex experiment, in which several variables were simultaneously assessed. For example, the inclusion of different milk batches gave a realistic interpretation of industrial variability and allowed to experiment the response of PTR-TOF-MS in a complex lifelike situation. Batch-to-batch variability of the milk was highlighted by PCA, which also denoted a temporal evolution of the VOCs profiles of the UHT LFMs during storage at $20^{\circ} \mathrm{C}$. Different VOCs profiling induced by the different commercial lactases employed did not emerge for most of the identified mass peaks. Possibly, the UHT treatment, which in this case occurred after lactose hydrolysis, inactivated most of the side activity of the lactase preparations. However, the different evolution of $\mathrm{m} / \mathrm{z} 107.049$ (benzaldehyde) during storage might be associated with the lactase preparations employed: Phenylalanine was pointed out as possible precursor of benzaldehyde formation, and it can derive from the proteolytic side activity originally present in the lactases. Therefore, the study suggested benzaldehyde as possible marker to monitor in UHT LFM if the aim is to attempt a discrimination based on the lactase preparations used. However, understanding whether the slight variations found in the study can affect the final quality of the products is still uncertain.

\section{ACKNOWLEDGEMENTS}

The present study is part of the $\mathrm{PhD}$ project of $\mathrm{R}$. B. financially supported by Wageningen University, Edmund Mach Foundation, and University Federico II of Naples. 


\section{ORCID}

Michele Pedrotti (D) https://orcid.org/0000-0002-9383-9504

Eugenio Aprea (D) https://orcid.org/0000-0003-3648-0459

Franco Biasioli (D) https://orcid.org/0000-0001-5715-9686

Vincenzo Fogliano (D) https://orcid.org/0000-0001-8786-9355

Flavia Gasperi (D) https://orcid.org/0000-0003-0055-9464

\section{REFERENCES}

1. Szilagyi A, Ishayek N. Lactose intolerance, dairy avoidance, and treatment options.Nutrients. 2018;10:1994. https://doi.org/10.3390/ nu10121994

2. Nielsen SD, Zhao D, Le TT, et al. Proteolytic side-activity of lactase preparations. Int Dairy J. 2018;78:159-168.

3. Jelen P, Tossavainen O. Low lactose and lactose-free milk and dairy products-prospects, technologies and applications. Aust J Dairy Technol. 2003;58:161-165.

4. Francis LL, Chambers DH, Kong SH, Milliken GA, Jeon IJ, Schmidt KA. Serving temperature effects on milk flavor, milk aftertaste, and volatile compound quantification in nonfat and whole milk. J Food Sci. 2005;70:s413-s418.

5. Valero E, Villamiel M, Miralles B, Sanz J, Martínez-Castro I. Changes in flavour and volatile components during storage of whole and skimmed UHT milk. Food Chem. 2001;72:51-58.

6. Jansson T, Rauh V, Danielsen BP, et al. Green tea polyphenols decrease Strecker aldehydes and bind to proteins in lactosehydrolyzed UHT Milk. J Agric Food Chem. 2017;65:10550-10561.

7. Troise AD, Bandini E, De Donno R, Meijer G, Trezzi M, Fogliano V The quality of low lactose milk is affected by the side proteolytic activity of the lactase used in the production process. Food Res Int. 2016;89(Pt 1):514-525.

8. Stressler T, Leisibach D, Lutz-Wahl S, Kuhn A, Fischer L. Homologous expression and biochemical characterization of the arylsulfatase from Kluyveromyces lactis and its relevance in milk processing. Appl Microbiol Biotechnol. 2016;100(12):5401-5414.

9. Santos MV, Ma Y, Caplan Z, Barbano DM. Sensory threshold of offflavors caused by proteolysis and lipolysis in milk 1. J Dairy Sci. 2003; 86:1601-1607.

10. Jensen $\mathrm{S}$, Jansson $\mathrm{T}$, Eggers $\mathrm{N}$, et al. Storage-induced changes in the sensory characteristics and volatiles of conventional and lactosehydrolyzed UHT processed milk. Eur Food Res Technol. 2015;240: 1247-1257.

11. Biasioli F, Gasperi F, Yeretzian C, Märk TD. PTR-MS monitoring of VOCs and BVOCs in food science and technology. TrAC - Trends Anal Chem. 2011;30:968-977.

12. Cappellin L, Loreto F, Aprea E, et al. PTR-MS in Italy: a multipurpose sensor with applications in environmental, agri-food and health science. Sensors (Switzerland). 2013;13:11923-11955.

13. Ellis AM, Mayhew CA. Proton transfer reaction mass spectrometry: principles and applications. Chichester, West Sussex, United Kingdom: Elsevier Ltd; 2013.

14. Aprea E, Biasioli F, Gasperi F, Mott D, Marini F, Märk TD. Assessment of Trentingrana cheese ageing by proton transfer reaction-mass spectrometry and chemometrics. Int Dairy J. 2007;17:226-234.

15. Boscaini E, Van Ruth S, Biasioli F, Gasperi F, Märk TD. Gas chromatography-olfactometry (GC-O) and proton transfer reactionmass spectrometry (PTR-MS) analysis of the flavor profile of grana padano, parmigiano reggiano, and grana trentino cheeses. J Agric Food Chem. 2003;51:1782-1790.

16. van Ruth SM, Koot A, Akkermans W, et al. Butter and butter oil classification by PTR-MS. Eur Food Res Technol. 2008;227:307-317.

17. Soukoulis C, Aprea E, Biasioli F, et al. Proton transfer reaction timeof-flight mass spectrometry monitoring of the evolution of volatile compounds during lactic acid fermentation of milk. Rapid Commun Mass Spectrom. 2010;24:2127-2134.

18. Soukoulis C, Biasioli F, Aprea E, et al. PTR-TOF-MS analysis for influence of milk base supplementation on texture and headspace concentration of endogenous volatile compounds in yogurt. Food Bioproc Tech. 2012;5(6):2085-2097.

19. Fabris A, Biasioli F, Granitto PM, et al. PTR-TOF-MS and data-mining methods for rapid characterisation of agro-industrial samples: influence of milk storage conditions on the volatile compounds profile of Trentingrana cheese. J Mass Spectrom. 2010;45(9):1065-1074.

20. Jansson T, Clausen MR, Sundekilde UK, et al. Lactose-hydrolyzed milk is more prone to chemical changes during storage than conventional ultra-high-temperature (UHT) milk. J Agric Food Chem. 2014;62:78867896.

21. Bergamaschi M, Bittante G, Gasperi F, et al. Effects of dairy system, herd within dairy system, and individual cow characteristics on the volatile organic compound profile of ripened model cheeses. J Dairy Sci. 2015;98(4):2183-2196.

22. Pedrotti M, Khomenko I, Cappellin L, et al. Rapid and noninvasive quality control of anhydrous milk fat by PTR-MS: the effect of storage time and packaging. J Mass Spectrom. 2018;53:753-762.

23. Cappellin L, Biasioli F, Fabris A, et al. Improved mass accuracy in PTRTOF-MS: another step towards better compound identification in PTR-MS. Int J Mass Spectrom. 2010;290:60-63.

24. Lindinger W, Hansel A, Jordan A. On-line monitoring of volatile organic compounds at pptv levels by means of proton-transfer-reaction mass spectrometry (PTR-MS) medical applications, food control and environmental research. Int J Mass Spectrom Ion Process. 1998;173:191-241.

25. Cappellin L, Karl T, Probst M, et al. On quantitative determination of volatile organic compound concentrations using proton transfer reaction time-of-flight mass spectrometry. Environ Sci Technol. 2012;46: 2283-2290.

26. van der Werf MJ, van den Berg RA, Hoefsloot HCJ, Westerhuis J, Smilde AK. Centering, scaling, and transformations: improving the biological information content of metabolomics data. BMC Genomics. 2006;7:1-15.

27. Jansson $\mathrm{T}$, Jensen $\mathrm{S}$, Eggers $\mathrm{N}$, et al. Volatile component profiles of conventional and lactose-hydrolyzed UHT milk-a dynamic headspace gas chromatography-mass spectrometry study. Dairy Sci Technol. 2014;94:311-325.

28. Rapisarda T, Pasta C, Belvedere G, et al. Variability of volatile profiles in milk from the PDO Ragusano cheese production zone. Dairy Sci Technol. 2013;93:117-134.

29. Contarini G, Povolo M. Volatile fraction of milk: comparison between, purge and trap and solid phase microextraction techniques. J Agric Food Chem. 2002;50(25):7350-7355.

30. Perkins ML, D'Arcy BR, Lisle AT, Deeth HC. Solid phase microextraction of stale flavour volatiles from the headspace of UHT milk. J Sci Food Agric. 2005;85:2421-2428.

31. Zardin E, Tyapkova O, Buettner A, Beauchamp J. Performance assessment of proton-transfer-reaction time-of-flight mass spectrometry (PTR-TOF-MS) for analysis of isobaric compounds in food-flavour applications. LWT- Food Sci Technol. 2014;56:153-160.

32. Aprea E, Romano A, Betta E, et al. Volatile compound changes during shelf life of dried Boletus edulis: comparison between SPME-GC-MS and PTR-ToF-MS analysis. J Mass Spectrom. 2015;50(1):56-64.

33. Van Aardt M, Duncan SE, Bourne D, et al. Flavor threshold for acetaldehyde in milk, chocolate milk, and spring water using solid phase microextraction gas chromatography for quantification. J Agric Food Chem. 2001;49:1377-1381.

34. Calvo MM, de La Hoz L. Flavour of heated milks. A Review Int Dairy J. 1992;2:69-81.

35. Deeth HC, Lewis MJ. High temperature processing of milk and milk products, 2017 
36. de Wit R, Nieuwenhuijse $\mathrm{H}$. Kinetic modelling of the formation of sulphur-containing flavour components during heat-treatment of milk. Int Dairy J. 2008;18:539-547.

37. Dekker PJT, Koenders D, Bruins MJ. Lactose-free dairy products: market developments, production. Nutrition and Health Benefits Nutrients. 2019;11:551.

38. Potineni RV, Peterson DG. Influence of thermal processing conditions on flavor stability in fluid milk: benzaldehyde. J Dairy Sci. 2010;88: 1-6.

39. Chu FL, Yaylayan VA. Model studies on the oxygen-induced formation of benzaldehyde from phenylacetaldehyde using pyrolysis GCMS and FTIR. J Agric Food Chem. 2008;56:10697-10704.

\section{SUPPORTING INFORMATION}

Additional supporting information may be found online in the Supporting Information section at the end of this article.

How to cite this article: Bottiroli R, Pedrotti M, Aprea E, Biasioli F, Fogliano V, Gasperi F. Application of PTR-TOF-MS for the quality assessment of lactose-free milk: Effect of storage time and employment of different lactase preparations. J Mass Spectrom. 2020;55:e4505. https://doi.org/ 10.1002/jms.4505 